\title{
Much Huffing about HIF: Oxygen Dependent Proline Hydroxylation and the Regulation of Hypoxia Inducible Factors
}

\author{
A review of: Jaakkola P, Mole DR, Tian YM, et al. 2001 Targeting of HIF-alpha to the von Hippel-Lindau \\ ubiquitylation complex by $\mathrm{O}_{2}$-regulated prolyl hydroxylation. Science 292:468-472; and Ivan M, Kondo K, Yang H, \\ et al. 2001 HIFalpha targeted for VHL-mediated destruction by proline hydroxylation: Implications for $\mathrm{O}_{2}$ sensing. \\ Science 292:464-468
}

$\mathrm{H}$ IF-1 (HYPOXIA INDUCIBLE factor 1) and HIF-2 (EPAS) are transcriptional activators that function as master regulators of response to oxygen homeostasis. They are heterodimers consisting of HIF- $1 \alpha$ and HIF- $1 \beta$ and HIF- $2 \alpha$ and HIF- $2 \beta$. HIF expression becomes evident in hypoxic cells which are exposed to low levels of oxygen $(40 \mathrm{~mm} \mathrm{Hg}$ partial pressure or less than $6 \% \mathrm{O}_{2}$ ) activating transcription of a number of genes involved in angiogenesis, erythropoiesis, glycolysis, energy metabolism, and vascular adaptation $(1,2)$.

The regulation of expression of the two HIFs until recently remained enigmatic in nature, because it was not known how cells were able to increase the titre of HIF. It was known that the level of expression was somehow controlled through the HIF- $1 \alpha$ subunit while the expression of the HIF- $1 \beta$ subunit was always at a higher level and constitutive in nature. In normoxia degradation of the HIF- $1 \alpha$ subunit was seen to occur after its binding to the von Hippel-Lindau factor, a component of the $\mathrm{E}_{3}$ ubiquitin ligase followed by ubiquitination and proteososomal destruction (2). In hypoxia this does not happen to the same extent but until recently no one knew why. Two studies recently published in Science, one by Jaakkola et al. (3) and the other by Ivan et al. (4) identify oxygen dependent proline hydroxylation as the key event tagging HIFs for destruction.

\section{BRIAN ROBINSON}

The part of HIF- $1 \alpha$ that binds to the von Hippel-Lindau factor, (residues 556-575) contains a motif DLDLEMLAPYIPMDDDFQL in which proline 564 is absolutely critical to the binding process $(3,4)$. These most recent studies showed that this proline is hydroxylated, binding takes place and the protein is degraded. If no hydroxylation occurs then the HIF- $1 \alpha$ binds to HIF- $1 \beta$ and HIF-1 directed transcription takes place. The hydroxylation of the critical proline in turn is determined by the level of oxygen since it is done by an oxygen-dependent prolyl oxidase, which presumably is only operative at normal oxygen tensions (3, 4). HIF-2 $\alpha$ has a similar motif, ELDLETLAPYIPMDGEDFQL, which undergoes proline hydroxylation before degradation. HIF-1 seems to be expressed ubiquitously in hypoxia as is HIF-2, while there is perhaps a bias toward endothelial cells for HIF-2 and perhaps a slightly different threshold for the appearance in hypoxia of the two proteins (5). There is also a difference in response of genes with HIF responsive elements (HREs). For example, the VEGF, which promotes angiogenesis, is much more responsive to HIF-2 than it is to HIF-1, while LDH-A which is important for glycolysis is equally responsive to both factors.
Many questions, however, remain unanswered about this new mechanism of target identification. Do other proteins become targeted in a similar way by proline hydroxylation? What is the identity of the prolyl hydroxylase in the cell that does this and does its reaction profile with respect to $\left[\mathrm{O}_{2}\right]$ explain the difference between normoxia and hypoxia for the survival of the HIF-a subunits?

1. O'Rourke JF, Tian YM, Ratcliffe PJ, Pugh CW 1999 Oxygen-regulated and transactivating domains in endothelial PAS protein 1: comparison with hypoxia-inducible factor-1 alpha. J Biol Chem 274:2060-2071

2. Wiesener MS, Turley H, Allen WE, Willam C, Eckardt KU, Talks KL, Wood SM, Gatter KC, Harris AL, Pugh CW, Ratcliffe PJ, Maxwell PH 1998 Induction of endothelial PAS domain protein-1 by hypoxia: characterization and comparison with hypoxia-inducible factor-1alpha. Blood 92:2260-2268

3. Jaakkola P, Mole DR, Tian YM, Wilson MI, Gielbert J, Gaskell SJ, Kriegsheim AV, Hebestreit HF, Mukherji M, Schofield CJ, Maxwell PH, Pugh CW, Ratcliffe PJ 2001 Targeting of HIF-alpha to the von Hippel-Lindau ubiquitylation complex by $\mathrm{O}_{2}$ regulated prolyl hydroxylation. Science 292:468472

4. Ivan M, Kondo K, Yang H, Kim W, Valiando J, Ohh M, Salic A, Asara, JM, Lane WS, Kaelin WG Jr 2001 HIFalpha targeted for VHL-mediated destruction by proline hydroxylation: Implications for $\mathrm{O}_{2}$ sensing. Science 292:464-468

5. Talks KL, Turley H, Gatter KC, Maxwell PH, Pugh CW, Ratcliffe PJ, Harris AL 2000 The expression and distribution of the hypoxia-inducible factors HIF-1 alpha and HIF-2 alpha in normal human tissues, cancers, and tumor-associated macrophages. Am J Pathol 157:411-421

Metabolism Research Programme

The Hospital for Sick Children

555 University Avenue

Toronto, Ontario M5G 1 X8

Canada 